\title{
Gallic Acid Derivatives (GADs) from Loranthus micranthus Linn. Parasitic on Hevea brasiliensis with Antioxidative Capacity
}

\author{
Matthias Onyebuchi Agbo ${ }^{1,2}$, Kenneth Maduabuchi Ezealisiji ${ }^{3}$, J oshua Elijah \\ Parker $^{4}$, Francis Ikechukwu Ukekwe ${ }^{5}$ and Wilfred Ofem Obonga ${ }^{1}$
}

${ }^{1}$ Department of Pharmaceutical and Medicinal Chemistry, University of Nigeria Nsukka, Enugu State Nigeria
${ }^{2}$ Institute of Pharmaceutical Biology and Biotechnology, Heinrich-Heine University, Düsseldorf, Germany
${ }^{3}$ Department of Pharmaceutical and Medicinal Chemistry, University of Port-Harcourt Rivers State
${ }^{4}$ Department of Biochemistry, University of Nigeria Nsukka, Enugu State, Nigeria
${ }^{5}$ Department Morbid Anatomy, University of Nigeria, Enugu Campus, P.M.B. 01129, Enugu 400241, Nigeria

Received: July 14, 2015; Accepted: November 19, 2015; Published (web): January 31, 2016

\begin{abstract}
Semi-preparative High Liquid Column Chromatographic separation of the ethyl acetate soluble fraction of a methanol extract of the leaves of Loranthus micranthus Linn. parasitic on Hevea brasiliensis (Willd. ex A. Juss.) led to the isolation of two gallic acid derivatives (1-2). The structures of the compounds were solved by using spectroscopic methods (1D and 2D NMR and mass spectroscopic data) as well as by comparison with literature values. The compounds were identified as 3,4,5-tri- $O$-methyl gallic acid (1) and methyl 3-O-methyl gallate (2). The antioxidant activity of the isolated compounds was evaluated by using DPPH assay. Compounds $\mathbf{1}$ and $\mathbf{2}$ showed strong antioxidative capacity with inhibitory concentration $\left(\mathrm{IC}_{50}\right)$ values of $10.0 \pm 0.03$ and $45.0 \pm 0.02 \mu \mathrm{M}$, respectively.
\end{abstract}

Key words: Loranthus micranthus, Structure elucidation, Gallic acid, Antioxidant, Oxidative stress

\section{INTRODUCTION}

Oxidative stress which results in excessive oxidative metabolism means an imbalance between pro-oxidants and antioxidant in which the prooxidant outweighs the antioxidant. ${ }^{1}$ This stress can be due to several environmental factors such as exposure to pollutants, alcohol, medications, infections, poor diet, toxins, radiation, etc. Oxidative stress causes injury to cells, induces gene mutation, and is involved in carcinogenesis by influencing intracellular signal transduction and transcription factors directly or indirectly via oxidants. Oxidative damage is caused by free radicals and reactive oxygen species, mostly generated endogenously. ${ }^{2}$

Correspondence to: Matthias Onyebuchi Agbo

Tel.: +234 8062661991

E-mail: matthias.agbo@unn.edu.ng

Dhaka Univ. J. Pharm. Sci. 14(2): 139-145, 2015 (December)
Free radicals and reactive oxygen species can be involved in a higher number of diseases via lipid peroxidation, protein peroxidation and DNA damage. ${ }^{3}$ Currently, there is great interest in finding antioxidants from natural sources to minimize oxidative damage to cells. Gallic acid derivatives (GADs) are naturally occurring polyphenols that act as antioxidants by efficiently scavenging free radicals. ${ }^{4}$ The antioxidant properties of these natural polyphenols are assumed to occur by hydrogen atom transfer and single-electron transfer mechanisms. ${ }^{4}$ Loranthus micranthus Linn is a hemi parasitic plant growing on different host trees and shrubs but depends on their host plant for water and mineral nutrition, despite the fact that they produce their own carbohydrates through photosynthesis. ${ }^{5}$ The isolation of polyphenols from L. micranthus parasitic on 
Hevea brasilensis and Kola acuminate with antioxidative potentials has been reported. ${ }^{6,7}$ The present research aims at isolating and characterization of GADs from $L$. micranthus parasitic on $H$. brasilensis and the evaluation of their antioxidant properties.

\section{MATERIALS AND MATERIALS}

General. Optical rotation of the isolated compounds was recorded on a Perkin-Elmer $241 \mathrm{MC}$ polarimeter. 1D and 2D NMR spectra of the isolated compounds were acquired on Bruker ARX (500 $\mathrm{MHz}$ ). Electrospray Impact Mass Spectrometric (ESI-MS) measurement was performed on a Thermofinnigan LCQ DECA mass spectrometer. Analytical High Performance Liquid Column Chromatography (HPLC) was performed with a HPLC system (Dionex, Munich, Germany). Semipreparative HPLC was performed on a MERCK HITACHI system equipped with a UV Detector. Vacuum liquid chromatography (VLC) was conducted on Silica gel $60(0.04-0.063 \mathrm{~mm}$ mesh Merck) using a glass column $(3 \times 30 \mathrm{~cm})$. Gel permeation column chromatography (CC) was carried out on Sephadex LH-20 (Merck, Germany) using a glass column $(3 \times 110 \mathrm{~cm})$.

Chemicals. Methanol, $n$-hexane, $n$-butanol, ethyl acetate, propyl gallate, spectral grade methanol (Sigma), DMSO- $d_{6}$ (Uvasol, Merck), methanol- $d_{4}$ (Uvasol, Merck), methanol LiChroSolv HPLC grade (Merck). All solvents used were of analytical grade and purchased from the Institute of Chemistry, Heinrich-Heine Universität, Düsseldorf Germany. The non-spectra grade solvents were distilled before use and special grades were used for spectroscopic measurements.

Plant material. Loranthus micranthus Linn. leaves parasitic on $H$. brasiliensis were collected from Enugu-Ezike in Enugu State, Nigeria. The leaves were identified by Mr. A.O. Ozioko of the International Center for Ethnobotanical and Ethnomedicine Development (InterCEED) Nsukka, Enugu State, Nigeria. A voucher specimen (LM1610) was deposited at the herbarium of the Institute. The leaves were air dried in the laboratory and pulverized using Thomas Willey Mill (England).

Extraction and solvent-solvent partitioning. Three hundred gram (300 g) plant powder was extracted with $2.5 \mathrm{~L}$ of methanol at room temperature for $48 \mathrm{hrs}$ by cold maceration. The extract was concentrated in vacuum at $40^{\circ} \mathrm{C}$ using rotary evaporator (Büchi Rotavapor R-200, Germany). The methanol extract $(42.0 \mathrm{~g}, 6.3 \%)$ was suspended in $400 \mathrm{ml}$ of $10 \%$ methanol-water mixture and successively fractionated with $n$-hexane $(5 \times 500 \mathrm{ml})$, ethyl acetate $(6 \times 500 \mathrm{ml})$ and $n$-butanol $(2 \times 500 \mathrm{ml})$ to yield $n$-hexane (HF, $4.45 \mathrm{~g}, 11.12 \%$ ), ethyl acetate (EF, 5.23g, 13.08\%), and $n-\mathrm{BuOH}(\mathrm{BF}, 1.02 \mathrm{~g}$, $2.55 \%)$ soluble fractions, respectively. Part of the ethyl acetate soluble fraction $(3.5 \mathrm{~g})$ was purified further by vacuum liquid chromatography using silica gel (500 g, 230-400 mesh, Merck) as the stationary phase. The column was then eluted with a gradient of $n$-hexane-ethyl acetate $(10: 0 \rightarrow 0: 10$, each $500 \mathrm{ml})$ and dichloromethane-methanol $(9: 1 \rightarrow 1: 9$, each 1000 $\mathrm{mL})$ to afford ten sub-fractions (EF1-EF10).

Isolation of the compounds. Fraction EF4 (44.60 mg) was purified by semi-preparative HPLC using $\mathrm{MeOH}-\mathrm{H}_{2} \mathrm{O}$ as mobile phase to afford compound 1 (2.90 mg). Also, fraction EF6 (348.5 $\mathrm{mg}$ ) was further purified by fractionation on Sephadex LH-20 (100\% $\mathrm{MeOH})$ to provide seven sub-fractions (EF6A-EF6G). Fraction EF6B (38.20 $\mathrm{mg}$ ) was purified by semi-preparative HPLC using $\mathrm{MeOH}-\mathrm{H}_{2} \mathrm{O}$ as mobile phase to yield compound 2 (9.20 mg).

Properties of 3,4,5-tri- $O$-methyl gallic acid (1). White amorphous solid; retention time $\left(t_{R}\right)$ of 19.4 min; $[\alpha]_{20}^{\mathrm{D}_{20}} 40.7$ (c 0.10, MeOH); $\mathrm{UV}_{\max }(\mathrm{MeOH})$ 216.6, $275.7 \mathrm{~nm} ;{ }^{1} \mathrm{H}$ NMR (DMSO-d $d_{6} \delta 3.87$ (s, 3H, $\mathrm{CH}_{3}$-4-OMe), 3.88 (s, 6H, 3/5 -OMe), 7.32 (s, 2H, $\mathrm{H}-2 / 6) . \quad \mathrm{MS} \quad(\mathrm{ESI}-\mathrm{MS}) \quad m / z \quad 213.0 \quad[\mathrm{M}+\mathrm{H}]^{+}$ $\left(\mathrm{C}_{10} \mathrm{H}_{12} \mathrm{O}_{5}+\mathrm{H}\right), 181[\mathrm{M}-32+\mathrm{H}]^{+}$(loss of- $\left.\mathrm{OCH}_{3}\right), 447$ $[2 \mathrm{M}+\mathrm{Na}]^{+}$.

Properties of methyl 3-O-methyl gallate (2). White amorphous solid; retention time $\left(t_{R}\right)$ of 15.0 $\min ;[\alpha]^{\mathrm{D}} 20-9.0$ (c $\left.0.02, \mathrm{MeOH}\right) ; \mathrm{UV}_{\max }(\mathrm{MeOH})$ 215.8, $274.4 \mathrm{~nm} ;{ }^{1} \mathrm{H}$ NMR ( $\delta$ values, $\left.\mathrm{CD}_{3} \mathrm{OD}\right)$, and 
${ }^{13} \mathrm{C}$ ( $\delta$ values, $\mathrm{CD}_{3} \mathrm{OD}$ ) NMR data: see table $1 . \mathrm{MS}$ (ESI-MS) $m / z, 199[\mathrm{M}+\mathrm{H}]^{+}\left(\mathrm{C}_{9} \mathrm{H}_{10} \mathrm{O}_{6}+\mathrm{H}\right)$.

Antioxidant assay. The antioxidant assay of the compounds was performed according to the procedure described by Agbo et al. ${ }^{8}$ Compounds 1-2 were dissolved in methanol to give a concentration of $1 \mathrm{mg} / 1000 \mu \mathrm{l}$ stock solution. Ten microliter $(10 \mu \mathrm{l})$ of these solutions was added to $490 \mu \mathrm{DPPH}$ solution $(4.5 \mathrm{mg} / 100 \mathrm{~mL})$ in an ependorf vial. The mixture was incubated for $5 \mathrm{~min}$ and the color change from deep violet to light yellow of the DPPH free radical was measured by recording the absorbance using a UV/Visible spectrophotometer (Perkin Elmer, Lambda 25) at $517 \mathrm{~nm}$. Prior to the measurement, the difference in absorption between a DPPH blank solution and the positive control (propyl gallate, 76 $\mu \mathrm{M})$ was determined. This difference was then taken as $100 \%$ antioxidative activity. The percent antioxidative activity was determined from the difference in absorption between the samples at 76 $\mu \mathrm{M}$ and the DPPH blank as follows:

$$
\mathrm{aA}(\mathrm{s})=\frac{\mathrm{AB}-\mathrm{Ap}}{\mathrm{AB}-\mathrm{Apos}} \times 100
$$

Where, $a \mathrm{~A}=\%$ antioxidative activity compared to the positive control, $\mathrm{AB}=$ absorption of the $\mathrm{DPPH}$ blank solution, $\mathrm{Ap}=$ absorption of the sample, and Apos $=$ absorption of the positive control (propyl gallate). Measurements were done in triplicates, and the $\mathrm{IC}_{50}$ values were determined by linear regression.

\section{RESULTS AND DISCUSSION}

The methanol extract of the leaves of Loranthus micranthus Linn leaves parasitic on $H$. brasiliensis was portioned with $n$-hexane, ethyl acetate and $n$ butanol respectively. The ethyl acetate fraction was purified and two compounds were obtained (Figure 1). By means of spectroscopic analysis, they were identified as 3,4,5-tri- $O$-methyl gallic acid (1) and methyl-3-O-methyl gallate (2). These secondary metabolites were isolated from the leaves of $L$. micranthus leaves parasitic on $H$. brasiliensis for the first time.
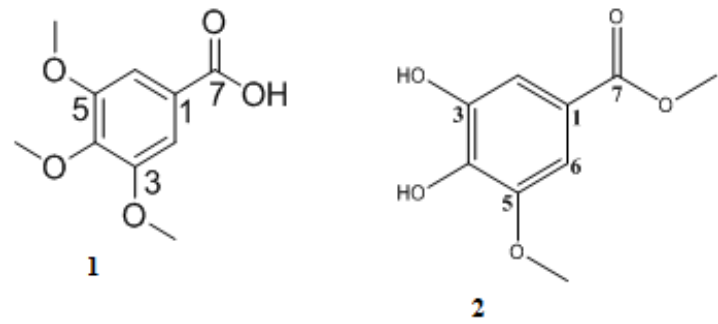

Figure 1. Chemical structures of compounds 1-2.

Antioxidant assay. The antioxidative potentials of the isolated compounds were assessed using DPPH assay and propyl gallate as a positive control.

Compound 1 was obtained as white amorphous solid. The ESI-MS exhibited molecular ion peaks at $m / z 213.0 \quad[\mathrm{M}+\mathrm{H}]^{+}$which is consistent with the molecular formula of $\mathrm{C}_{10} \mathrm{H}_{12} \mathrm{O}_{5}$. UV spectra displayed characteristic absorption bands for the benzoid nucleus and $\mathrm{C}=\mathrm{O}$ chromophores at 217 and $276 \mathrm{~nm}$ respectively (Figure 2). The ${ }^{1} \mathrm{H}$ - NMR spectrum of compound 1 indicated a singlet at $\delta_{H} 7.32 \mathrm{ppm}$ integrating as $2 \mathrm{H}$, suggesting the presence of tetrasubstituted benzene ring. The proton signals at $\delta_{H}$ $3.88 \mathrm{ppm}(6 \mathrm{H}, \mathrm{s})$ suggested the presence of two equivalent aromatic methoxyl groups (3/5-OMe) and another three proton singlet at $\delta_{H} 3.67$ revealed the presence of another methoxyl at $\mathrm{C}-4$, respectively. The mass spectrum showed fragments at $m / z 181$ [M$32+\mathrm{H}]^{+}\left(\right.$loss of $-\mathrm{OCH}_{3}$ unit $) ; m / z 447[2 \mathrm{M}+\mathrm{Na}]^{+}$ (Figure 3). The NMR data of compound 1 agreed with well published values for methyl 3,4,5-tri-Omethyl gallate. $^{9}$ Therefore, compound $\mathbf{1}$ was characterised as 3,4,5-tri- $O$-methylgallic acid.

Compound 2 was obtained as a white amorphous solid. The ESI-MS of compound $\mathbf{2}$ exhibited molecular ion peak at $\mathrm{m} / \mathrm{z} 199.1[\mathrm{M}+\mathrm{H}]^{+}$suggesting that the molecular mass is $190 \mathrm{~g} / \mathrm{mol}$ with a molecular formula of $\mathrm{C}_{9} \mathrm{H}_{10} \mathrm{O}_{5}$ and having five degree of unsaturation. The ${ }^{1} \mathrm{H}$ NMR spectrum showed a singlet at $\delta_{H} 7.32 \mathrm{ppm}$ integrating for $2 \mathrm{H}$, suggesting the presence of tetra-substituted benzene ring. The proton signals at $\delta_{\mathrm{H}} 3.87 \mathrm{ppm}(3 \mathrm{H}, \mathrm{s})$ and $\delta_{\mathrm{H}}$ $3.84 \mathrm{ppm}(3 \mathrm{H}, \mathrm{s})$ in the ${ }^{1} \mathrm{H}$ NMR spectrum and the carbon signals at $\delta_{C} 52.8 \mathrm{ppm}$ and $\delta_{C} 57.2$ suggested the presence of an ester methoxyl and an aromatic 

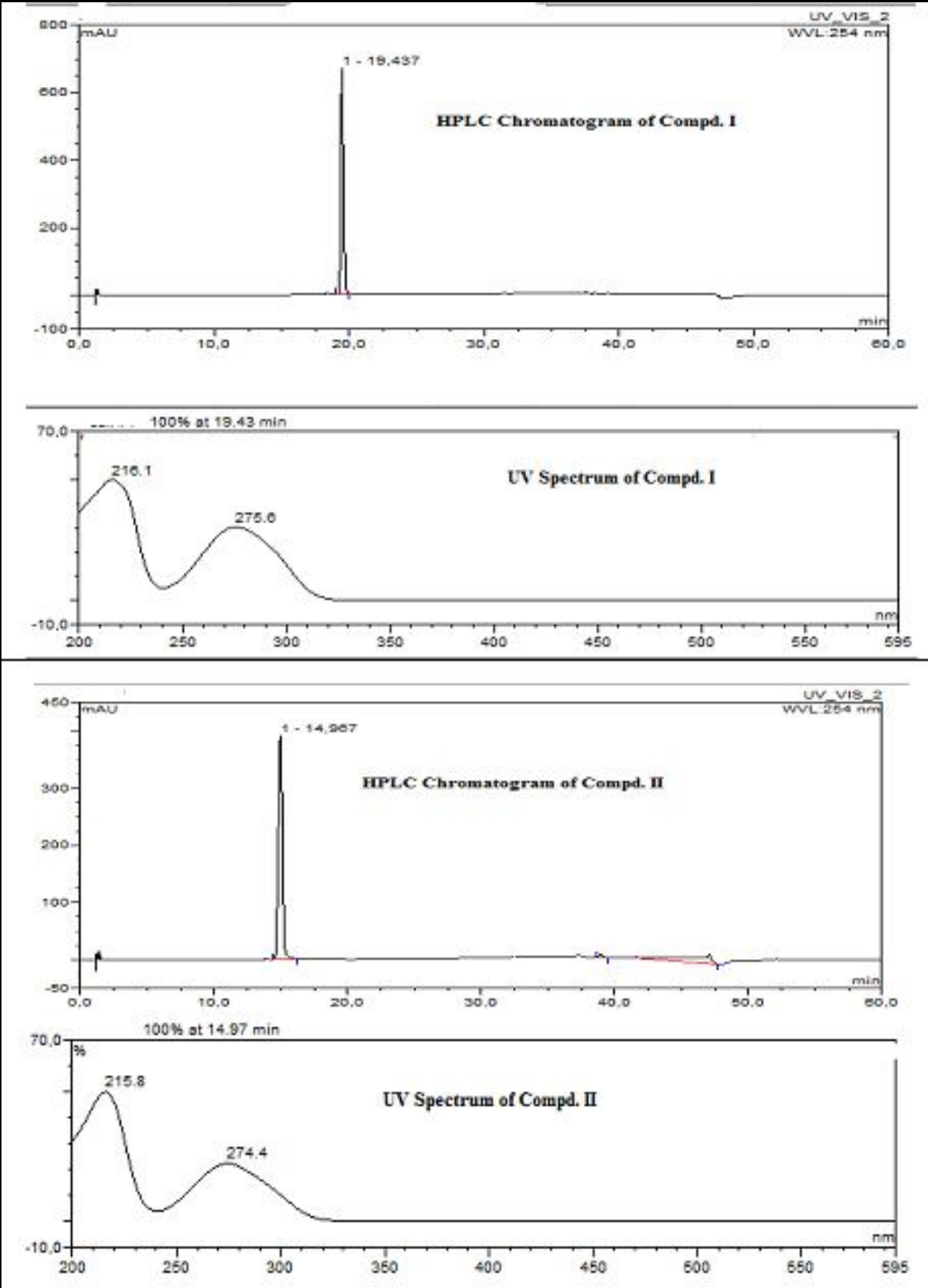

Figure 2. HPLC and UV analysis of Compounds 1 and 2. HPLC column: C18 $(5 \mu \mathrm{m}) 3000 \mathrm{x} 8 \mathrm{~mm}$; gradient elution: methanol (solvent A) and nano pure $\mathrm{H}_{2} \mathrm{O}$ (solvent B), detection wavelength: $254 \mathrm{~nm}$. Flow-rate: $5.0 \mathrm{~mL} / \mathrm{min}$. The ethyl acetate fraction was purified by semi-preparative HPLC to afford compounds $\mathbf{1}$ and $\mathbf{2}$.

methoxyl groups, respectively (Table 1 ). The ${ }^{13} \mathrm{C}$ NMR spectrum of compound 2 exhibited resonances for nine types of carbons comprising a $\mathrm{C}=\mathrm{O}$ signal at $\delta c 169.0$ (indicating the presence of carbonyl ester), two unsymmetrical oxygenated aromatic carbon signals at $\delta c 146.4$ (C- 3) and $\delta c 140.8$ (C-4); one quaternary aromatic carbon signal at $\delta c 121.6(\mathrm{C}-1)$ and two unsymmetrical aromatic methine carbon 


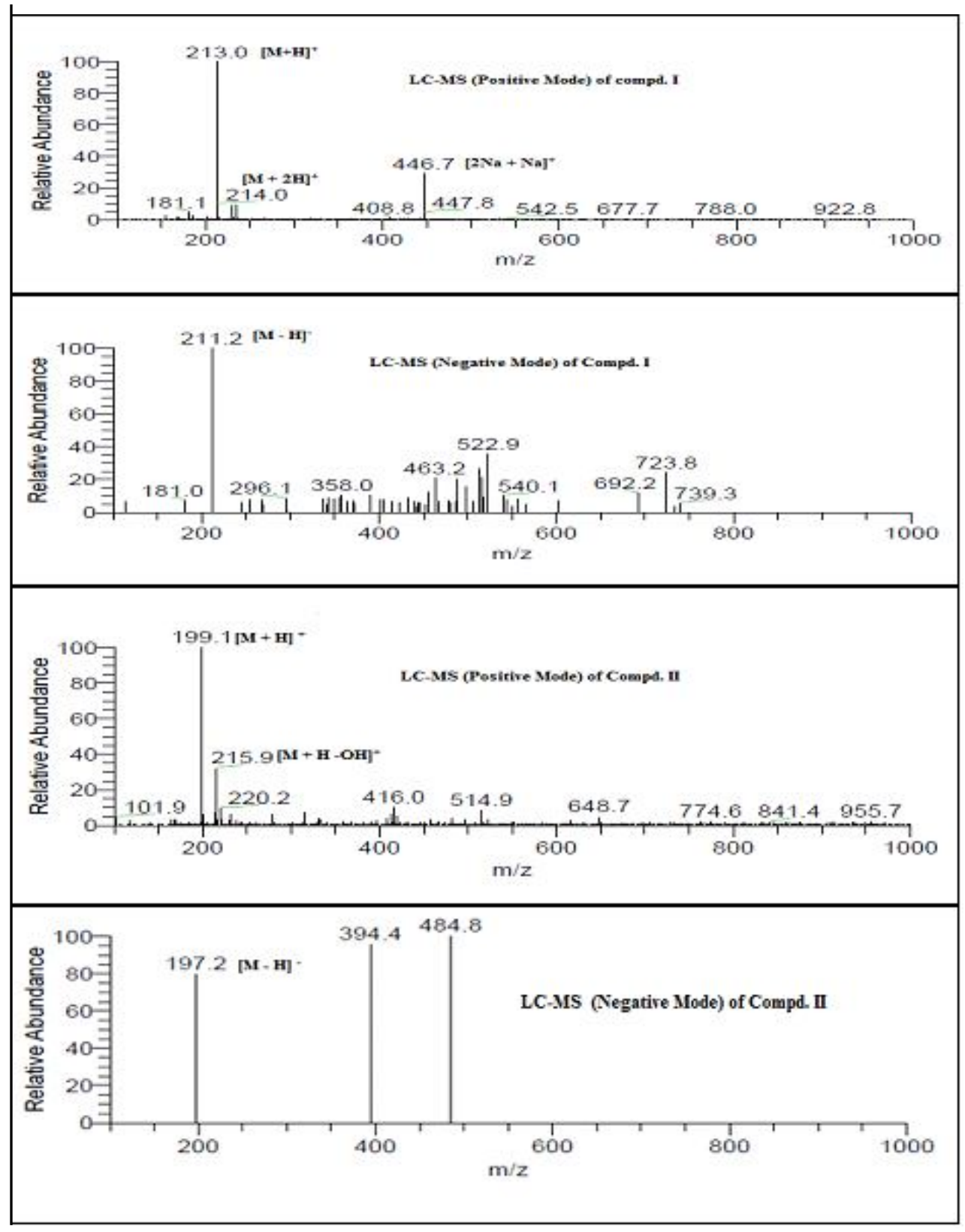

Figure 3. LC-MS Data of Compounds 1-2.

signals at $\delta c 112.4$ and 106.2 (C-2 and C-6) (Table 1). Based on HMBC spectrum, ${ }^{3} \mathbf{J}$ correlations were observed between methine aromatic protons signal at $\delta_{H} 7.17$ with the carbonyl ester carbon signal at $\delta c$ 169.0. Further analysis of HMBC spectrum showed correlation between the ester methoxyl proton signals at $\delta_{H} 3.87$ with carbonyl ester carbon signal at $\delta c$ 169.0 (Figure 4). Similar correlations were also observed in methyl gallate structure elucidation as reported by Mohd et al. ${ }^{10}$ thus compound $\mathbf{2}$ is elucidated as methyl 3-O-methylgallate.

Gallic acid and its derivatives are widely present in the plant kingdom and are known to display antioxidant activity by the ability to counteract the damaging effects of free radicals in tissues and thus 
are believed to protect against cancer, arteriosclerosis, heart disease, and several other diseases. ${ }^{9}$ Among polyphenols, gallic acid derivatives are a well-known group of naturally occurring compounds which have been found in many phytomedicines. ${ }^{11}$ The antioxidant activity of plant extracts or isolated secondary metabolites can be determined using different methods. The commonest

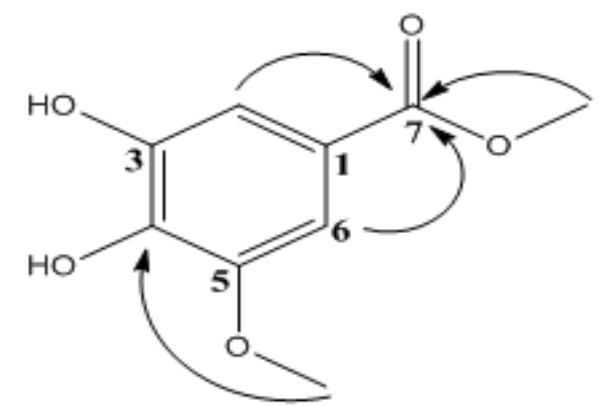

Figure 4 . Key HMBC $(\mathrm{H} \rightarrow \mathrm{C})$ correlations of compound 2

Table 1. ${ }^{1} \mathrm{H}(500 \mathrm{MHz}),{ }^{13} \mathrm{C}(125 \mathrm{MHz})$ NMR and HMBC data of compound 2.

\begin{tabular}{llll}
\hline Position & $\delta_{C}$ & $\delta_{H}(J \mathrm{in} \mathrm{Hz})$ & HMBC \\
\hline 1 & 121.6 & - & - \\
2 & 106.2 & $7.17, \mathrm{~d}(1.9)$ & $4,5,7$ \\
3 & 149.5 & - & - \\
4 & 140.8 & - & - \\
5 & 146.4 & - & - \\
6 & 112.4 & $7.17, \mathrm{~d}(1.9)$ & $4,5,7$ \\
7 & 169.0 & - & - \\
$3-O M e$ & 57.2 & $3.84, \mathrm{~s}$ & - \\
$7-$ OOMe & 52.9 & $3.87, \mathrm{~s}$ & 7 \\
\hline
\end{tabular}

Table 2. Antioxidant assay of compounds 1-2.

\begin{tabular}{cc}
\hline \multirow{2}{*}{ Compounds } & Antioxidative potential \\
\cline { 2 - 2 } & $\mathrm{IC}_{50}(\mu \mathrm{M})$ \\
\hline $\mathbf{1}$ & $10.0 \pm 0.03$ \\
$\mathbf{2}$ & $45.0 \pm 0.02$ \\
Chlorogenic acid & $67.9 \pm 0.10$ \\
\hline
\end{tabular}

method is the chemical assay, which is based on the ability, to scavenge various kinds of free radicals and uses DPPH (1, 1-diphenyl-2-picrylhydrazyl). ${ }^{12} \mathrm{DPPH}$ is scavenged by antioxidants either by donating a hydrogen atom or transferring of an electron to the odd electron of nitrogen to neutralize free radical character, leading to the loss of its purple color to the yellow colour of a residual picryl group. This change in the colour can be quantified spectrophotometrically by a decrease in absorbance at wavelength $517 \mathrm{~nm} .{ }^{13}$ The antioxidant activities of the isolated compounds were assayed using the DPPH assay with propyl gallate as positive control. The $\mathrm{IC}_{50}$ isolated compounds (1-2) were found to be $10.0 \pm 0.03$ and $45.0 \pm 0.02 \mu \mathrm{M}$, respectively. The isolated compounds were found to exhibit more antioxidative potentials than the reference compound (chlorogenic acid) with $\mathrm{IC}_{50}$ value of $67.9 \pm 0.10 \mu \mathrm{M}$ (Table 2) in DPPH assay. The result indicates that gallic acid derivatives from Nigerian mistletoe could be used in the management of some ailments caused by oxidative stress.

\section{CONCLUSION}

The present study has revealed that gallic acid derivatives isolated from $L$. micranthus parasitic on $H$. brasiliensis possesses antioxidative potentials. Work is on-going with a view to compounding Mistletoe tea that could be used to scavenge free radicals from the body.

\section{ACKNOWLEDGEMENT}

The authors are grateful to Prof. Dr. Peter Proksch of the Institute of Pharmaceutical Biology and Biotechnology, Heinrich-Heine University, Düsseldorf, Germany for allowing us to use his laboratory in carrying out this research work.

\section{REFERENCES}

1. Noda, N. and Wakasugi, H. 2001. Cancer and oxidative stress. JMAJ. 44, 535-539.

2. Aniya, Y. 2002. Antioxidants in traditional foods and medicinal plants from Okinawa. In: D. Itokazu, H. Sho, \& Y. Nakahara (Eds.), Proceding of Okinawa International Conference on Longevity. p. 50

3. Ganapaty, S., Ramaiah, M., Yasaswini, K., Kuthakki, V.K. and Harikrishnareddy D. 2013. Preliminary qualitative, quantitative phytochemical analysis and in vitro antioxidant potential of methanolic extract of Cuscuta epithymum (L.) whole plant. Intl. J. Pharmacogn. Phytochem. Res. 5, 236241. 
4. Kalita, D., Kar, R. and Handique, J.G. 2012. A theoretical study on the antioxidant property of gallic acid and its derivatives. J. Theoret. Comput. Chem. 11, 391-402.

5. Agbo, M.O., Nworu, C.S., Okoye, F.B.C., Osadebe, P.O. 2014. Isolation and structure elucidation of polyphenols from Loranthus micranthus Linn parasitic on Hevea brasiliensis with anti-inflammatory property. EXCLI J. 13, 859-868.

6. Omeje, E.O., Osadebe, P.O., Akira, K., Amal, H., Adbessamad, D., Esimone, C.O., Nworu, C.S. and Proksch, P. 2012. Three (-) - catechin- $O$-rhamnosides from the Eastern Nigeria Mistletoe with potent immunostimulatory and antioxidant activities. Biomolecules 1, 1-6.

7. Agbo, M.O., Lai, D., Okoye, F.B.C., Osadebe, P.O. and Proksch, P. 2013. Antioxidative polyphenols from Nigerian mistletoe Loranthus micranthus Linn parasitizing on Hevea brasiliensis. Fitoterapia 86, 78-83.

8. Agbo, M.O., Uzor, P.F., Akazie-Nneji, U.N., Eze-Odurukwe, C.U., Ogbatue, U.B. and Mbaoji E.C. 2015. Total phenolic and flavonoid contents in selected Nigerian medicinal plants. Dhaka Univ. J. Pharm. Sci. 14, 35-41.
9. Patrick-Iwuanyanwu, K.C., Onyeike, E.N. and Adhikari, A. 2014. Isolation, identification and characterization of gallic acid derivatives from leaves of Tapinanthus bangwensis. J. Nat. Prod. 7, 14-19.

10. Mohd, N.H.D., Mohd, L.J., Mohd, N.J., Normah, A. and Nurul, N.M.F. 2011. Identification and isolation of methyl gallate as a polar chemical marker for Labisia pumila Benth. J. Trop. Agric. Food Sci. 39, 279-284.

11. Khaledi, H., Alhadi, A.A., Yehye, W.A., Ali, H.M., Abdulla, M.A. and Hassandarvish, P. 2011. Antioxidant, cytotoxic activities, and structure-activity relationship of gallic acidbased indole derivatives. Arch. Pharm. Chem. Life Sci. 344, 703-709.

12. Kim, D.O., Lee, K.W., Lee, H.J. and Lee, C.Y. 2002. Vitamin C equivalent antioxidant capacity (VCEAC) of phenolic phytochemicals. J. Agri. Food Chem. 50, 37133717.

13. Agbo, M.O., Nnadi, C.O., Ukwueze, N.N. and Okoye, F.B.C. 2014. Phenolic constituents from Platycerium bifurcatum and their antioxidatant properties. J. Nat. Prod. 7, 48-57. 